\title{
Title: The insurance industry and unconventional gas development: Gaps and recommendations
}

\begin{abstract}
The increasingly growing and controversial practice of natural gas development by horizontal drilling and high volume hydraulic fracturing ('fracking') faces a severe environmental insurance deficit at the industry level. Part of this deficit is arguably inherent to the process, whereas another part is caused by current risk information shortfalls on the processes and impacts associated with development. In the short and long terms, there are several conventional and unconventional methods by which industry-level and governmental-level policy can insure against these risks. Whilst academic attention has been afforded to the potential risks associated with unconventional natural gas development, little consideration has been given to the lack of insurance opportunities against these risks or to the additional risks promulgated by the dearth of insurance options. We chronicle the ways in which insurance options are limited due to unconventional gas development, the problems caused by lack of insurance offerings, and we highlight potential policy remedies for addressing these gaps, including a range of government- and industry-specific approaches.
\end{abstract}

Keywords: Insurance; liability; hydraulic fracturing; fracking; risks; market gap

\section{Highlights:}

- A gap exists in provision of liability insurance for 'fracking'-related risks

- The market gap is due primarily to uncertainties about probabilistic risk 
- Insurance for risks similar to 'fracking' highlight potential policy options

- Government regulation and/or industry agreements can effectively fill the gap

- Policies on insurance and liability coverage necessitate ethical considerations

\section{Introduction}

High volume, horizontal, slick-water hydraulic fracturing is a controversial form of natural gas and oil development in part because of risks associated with it, although limited information exists about many such risks. Most prominently, water pollution has resulted from and happened during the shale gas development process, though less often because of structural issues with well casings that lead to methane (Llewellyn et al. 2015) or fluid migration (Darrah et al. 2014, Jackson et al. 2013), and more often because of how wastewater known as fracking fluid (a mixture of water, hazardous chemicals, and sand) is handled before and after fracturing (Souther et al. 2014).

Explosions due to unexpected areas of high pressure known as blowouts may occur, releasing fracking fluids into the nearby environment and in rarer cases may pollute underground aquifers (Dana and Wiseman 2014). More commonly, used fracking fluid (known as flowback or produced water) contaminates surface waters after being spilled during transportation away from well sites (Dana and Wiseman 2014). It is released due to human error (as opposed to container or other equipment failure) and is spilled in relatively small quantities (less than 1,000 gallons) (U.S. Environmental Protection Agency 2015). Natural gas development companies are responsible for damages to water supplies, and these risks are likely quantifiable to some extent, but little to no probabilistic information has been compiled. Rozell and Reaven (2012) do estimate a best-case scenario of $200 \mathrm{~m}^{3}$ of contaminated fluids released per well, though they 
note imprecision in their underlying data. Many suits have been filed against companies, though few have been settled, giving little current semblance of a baseline and no maximum estimate for damages (Nicholson et al. 2012).

Drinking water contamination from methane migration, although it has been deemed by the US EPA and state health agencies to not pose a risk to human health, can lower local oxygen concentrations and pose fire and explosion risks in areas in proximity to wells (Jo et al. 2013). Due to interaction with highly saline environments in the shale formations, methane migrating from shale gas extraction could also potentially form toxic trihalomethanes, although there is no documented evidence of this to date (Vengosh et al. 2014). It is still uncertain whether methane migration is inherent to the 'fracking' process or just results from inadequate well safety measures (Osborn et al. 2011). Cases such as Martin v. Reynolds have established that in the state of Oregon, the entry of invisible gasses such as methane and subsequent damages caused by these gasses amount to trespass. Although what constitutes a 'trespass' varies slightly by state, Martin v. Reynolds demonstrates legal precedent associated with methane pollution risk (Ingelson et al. 2010).

Beyond water contamination issues, earthquakes capable of causing damage have occurred with an increasing frequency in regions that use injection wells to dispose of wastewater from 'fracking' sites, in addition to produced water from conventional oil development (McGarr et al. 2015, Skoumal et al. 2015). Arkansas has since effectively banned the practice (Zilk 2011) and Ohio has regulated it heavily (Ohio Dept. of Natural Resources 2015). Oklahoma and Texas are perhaps best known for having experienced earthquake 'swarms' likely associated with injection wells (McGarr et al. 2015, Keranen et al. 2014, Sumy et al. 2014, Frohlich et al. 2014). Attributing causation from individual wells to unique 
earthquake events is difficult if not impossible to prove currently, so this poses little risk to natural gas development (NGD) companies, though United States Geological Survey projections expect that regions of Oklahoma and Kansas face the same 5-12\% chance of property damage from induced seismicity alone as properties in California face from natural seismicity alone (Petersen et al. 2016).

Finally, 'fracking' may be associated with risks to human health (Adgate et al. 2014, Jacquet and Stedman 2014, Maryland Institute for Applied Environmental Health 2014, New Brunswick Department of Health 2012). Although there is a dearth of research into the matter, health issues such as gastrointestinal, neurological, sensory, and vascular problems have emerged, respiratory problems have been frequently reported, and there is potential for long term cancer risks to emerge (Rafferty and Limonick 2013). Further research is necessary to establish any extent of risk connected with 'fracking' and its associated processes; these anecdotal cases and relatively isolated studies are worth acknowledging for understanding possible risk areas.

\subsection{Currently available insurance options}

Many insurers do not offer environmental insurance necessary to cover the aforementioned risks, though those that do have many products that can address and cover risks for NGD companies.

The product featuring most prominently for NGD companies is an Environmental Impairment Liability (EIL) policy which provides coverage for damages to other parties caused by pollution conditions originating from a well site (Dybdahl 2011, OECD 2003, Swartz 2011). 'Pollution' in this context consists of any chemicals, liquids, gasses, and acids that could be used in the development process, a definition broad enough such that companies such as golf courses, 
factories, farms, and oil refineries utilise similar policies (Dybdahl 2011). EIL policies are limited by the need of insurers to both be able to quantify risks and to know the highest possible damages that a claim could carry for the insurer; limited current information on impacts of shale gas development therefore inhibits the potential for NGD companies that use hydraulic fracturing to be issued EIL policies (Gupta 2008, Nationwide 2012, OECD 2003). Oil and gas companies in general accounted for as high as $40 \%$ of EIL policies issued from 2011 to 2013, but this is mostly due to 'conventional' development (Nationwide 2012).

An option for NGD companies similar to an EIL policy is a Commercial Pollution Legal Liability (CPLL) policy. CPLL policies cover the same conditions as EIL policies, except for pollution damages that affect the company itself such as damages to the environment immediately surrounding a well in the event of a blowout (Waeger 2013). CPLL policies face similar limitations to EIL policies in terms of information needs and issues for insurers. Also available and of interest for both NGD companies and for the transportation industry associated with 'fracking' is Transportation Insurance, which covers risks associated with accidents that may occur during the transportation of hazardous substances (OECD 2003). Such policies are rarely issued because of lacking information about the highest possible damages that can be associated with a claim, but could be useful for companies depending on how the unconventional fossil fuel extraction industry develops in the future.

If risk or uncertainty associated with 'fracking' proves to be too large for the insurance industry to capably handle, one alternative for NGD companies is catastrophe-linked (CAT) securities. CAT securities are sold by insurance companies to separate asset markets and are often purchased because catastrophe risk is thought to be independent of financial market risk (Eberl and Jus 2012, Weiss et al. 2013). These securities either pay off for bondholders at the 
end of a period if no catastrophe occurs or are used to cover the costs of a catastrophe if one does occur. These securities may only be useful for large scale operations - a majority of all CAT securities issued have been for catastrophes on the scale of high magnitude earthquakes and coastal hurricanes which may cause hundreds of millions to billions of dollars in damages (Artemis 2015). Therefore, whilst the opportunity exists to rely on CAT bonds, fracking litigation has not reached payout levels on the scale of hurricane or major earthquake damages; thus, it likely does not make sense on the side of NGD companies to pursue this insurance strategy currently.

\section{Market gap: Failures of insurance markets to address 'fracking' risks}

Although scattered options are available to insure NGD companies, few firms are actually insured for environmental damages specifically. Much of this dearth in coverage is caused by the outright unwillingness of insurers to cover NGD companies, as only five or six insurers will write EIL policies for NGD companies (McLeod 2013).

This unwillingness stems from the aforementioned lack of information and extreme uncertainty. Insurers such as Nationwide have made publicly known that they do not insure unconventional natural gas and oil development because the vast uncertainty associated with those industries is too large for them to charge a reasonable premium. Insurers rarely work with oil and gas development companies and often have little background with the unique risks associated with development generally, which explains the unwillingness specifically for unconventional NGD companies (Esch 2012, Nationwide 2012). Because of what is known as adverse selection, those insurers who do insure NGD companies will additionally need to work 
with the fact that only the highest risk companies will seek out environmental insurances (OECD 2003).

Specialty insurers and independent information service companies are likely to develop improved risk profiles of oil and gas development companies as development operations expand, liabilities emerge, and risks become better understood. Whether new products will be created at acceptable prices for higher risk NGD companies, and whether products or risk mitigation strategies will be implemented on a socially reasonable timeline, are factors for policymakers to consider.

Furthermore, inadequate public knowledge about shale gas development, the associated processes, and their impacts creates additional risks that more commonplace industries do not face. Because of what is called public moral hazard, areas with disproportionate fears about 'fracking' are more likely to sue NGD companies for health and environmental damages that were not actually caused by company activities (Kunreuther 1997). Political uncertainty can also arise from poorly informed political decision making, which creates uncertainty for insurers attempting to write policies specific to unconventional fossil fuel extraction - if policy shifts rapidly, insurers' efforts could be wasted (Carter 1986).

\section{Pathways forward: Potential policies to fill the insurance gap}

To develop practical alternative schemes to traditional environmental insurance for NGD companies, it is useful to examine legislation and agreements in other, similar areas to shale gas development via high-volume hydraulic fracturing.

Working within traditional insurance, governments have the option of subsidising companies' insurance, as the governments of Massachusetts, Wisconsin, and New York have 
done for brownfield remediation (Waeger 2013). Governments can also effectively subsidise NGD companies' insurance by setting a cap on companies' liability for catastrophic events such as the federal government did with the Price Anderson Act for nuclear energy utilities, the National Childhood Vaccine Injury Act for vaccine manufacturers, and the Supporting AntiTerrorism by Fostering Effective Technologies Act for anti-terrorism technological development (Ingelson et al. 2010). Each of these alternatives subsidise the NGD industry and so depend on a certain level of political support for unconventional energy development.

Governments can additionally create publicly managed insurance entities specifically for limited 'fracking insurance', similar to the California Earthquake Authority, which was formed to offer limited earthquake coverage to Californians (California Earthquake Authority 2015). Such an entity would cover some of the risks associated with 'fracking' to a smaller extent than traditional EIL policies and would be able to better familiarise itself with the specific risks of shale gas/oil development. Furthermore, legislation can limit what kinds of exemptions insurance companies can add to general, non-environmental policies such as CAL. INS. Code $\S 10088.5$, which forbids insurers from excluding fire damages resulting from earthquakes from homeowner's policies without earthquake insurance (California Law n.d.). An April, 2015 notice from the Pennsylvania Insurance Department similarly forbids the exclusion of induced earthquakes from earthquake endorsements to homeowners' insurance policies (Ha 2015). These alternatives require little political support for unconventional energy development and work within structures of traditional insurance; yet, they do not fully address issues with insuring 'fracking' in that they fail to comprehensively cover potential risks.

Finally, in the event that traditional insurance proves impossible or otherwise fails to cover 'fracking' risks, unconventional NGD companies can form mutual insurance companies or 
associations similar to the European Mutual Association for the Nuclear Industry and Nuclear Electric Insurance Limited, both of which are policy-holder owned, private entities that pool risk among nuclear energy utilities (Eberl and Jus 2012). These agreements provide insurance at the industry level and incentivise peer monitoring that may lead to outright risk reductions. Risk retention groups (RRGs), organized under the federal Liability Risk Retention Act of 1986, are often organised as mutual insurance companies and allow for risk pooling of smaller subsets of industries and the filling of short term gaps in liability insurance coverage. Although RRGs cannot access state guaranty funds in the event of insolvency, they are able to write insurance in all states despite only effectively being regulated by a single domiciliary state; this both decreases regulatory compliance costs and would, for instance, allow a single firm to become active in states with ongoing shale gas development faster than an ordinary mutual insurance company (Leverty 2012).

Mutual insurance companies and RRGs are an extreme alternative to what currently exists, which is the use of government as the reinsurer of last resort - in the event that a catastrophe occurs and a NGD firm doesn't have assets to cover the damages, government intervenes and covers clean-up costs as it does for other industries under the US's Comprehensive Environmental Response, Compensation, and Liability Act [CERCLA] (Vann et al. 2014). Relying on government as an insurer of last resort effectively handles insurance without insurers, distributing risk among firms and taxpayers respectively instead of a larger market of insurers. This options is simple, but may not be preferable to those discussed above for reasons such as distribution of costs.

\section{Ethical considerations}


The decision of how or even whether to create policy to address issues with unconventional natural gas development and insurance should be grounded in a moral discussion that addresses potential large scale issues and trade-offs in such policies. Fundamentally, the issue of how to insure natural gas development begs the question of whether shale gas development by hydraulic fracturing should continue: such a question is beyond the scope of this 'short communication'; this article is neither an endorsement nor censure of the practice.

If development continues, policymakers must weigh the role of insurance as a tool for protection against its role as a potential disincentive for risk mitigation - if NGD companies' practices are insured, they may take fewer voluntary actions to improve risk management. If this occurs, the outcome of making insurance available might be a net loss for society - losses, strife, and hardships may be met with payments from insurers, but may cause irreparable damage or simply offer inadequate compensation. Non-existent damages are better than ones compensated for due to insurance.

An extreme case of insurance leading to worse outcomes occurs where NGD companies find it profitable to be deliberately negligent with safety measures given the risk of being caught by the insurer (and thus having the policy voided if they are caught). If this occurs, the presence of an insurance market for NGD companies will have created additional external risk - again, a net loss for society, and one that disproportionally affects those uninvolved in development. The likelihood of such a scenario manifesting is minute, yet worth addressing.

With all policies, policymakers should be mindful of the implications and unintended consequences of different approaches, and of how these implications may differ across stakeholder groups. 


\section{5. 'Conclusion and Policy Implications'}

We have chronicled the state of insurance markets for covering risks associated with unconventional gas development; insurance options are limited and many gaps exist, primarily due to limited information on risks associated with development. In seeking to fill these insurance gaps, we have identified several pathways forward, including actions that industry and government actors can take. Government regulation may be necessary at local, state, and/or national levels (Hagström and Adams 2012, Wiseman 2014), whether by: subsidising insurance by setting a cap on liability, limiting exclusions from general insurance policies for risks due to 'fracking', or functioning as an insurer of last resort. Government could also address the insurance gaps in a more long-term way by providing incentives for private and public research into probabilistic 'fracking'-related risk. Only when quantitative risk data is more readily available will mainstream insurance options for unconventional energy development increase substantially.

If politicians and policymakers determine that shale gas development ought to develop faster, executive and legislative action could limit companies' liability for damaging incidents or subsidise environmental insurance. Governments could alternatively or additionally provide limited, mandated, publically-managed 'fracking insurance' for homeowners, renters, and NGD companies to ensure that the general citizenry is protected against the range of potential risks associated with development.

Finally, regardless of a government's particular stance on unconventional energy development, if development is occurring within that government's jurisdiction, we strongly encourage implementation of public information programs about both 'fracking'-related risks and about what homeowners' insurance will cover in the event of a 'fracking'-related damaging 
incident. Whilst the extent to which government intervention in markets is merited remains unclear (Schremmer 2011), a procedurally just approach to energy development demands that the public be informed about what liability they are potentially exposed to via this novel form of energy extraction.

\section{REFERENCES}

Adgate J., Goldstein, B., McKenzie, L., 2014. Potential public health hazards, exposures and health effects from unconventional natural gas development. Environ. Sci. Technol. 48, 8307-8320.

Artemis, 2015. Catastrophe Bond \& Insurance-Linked Securities Deal Directory. Web. Retrieved from: <http://www.artemis.bm/deal_directory>. Accessed on: 23 July 2015.

California Earthquake Authority. 2015. Our History. Web. Retrieved from: <http://www.earthquakeauthority.com/whoweare/Pages/history.aspx>. Accessed on: 23 July 2015.

California Law, n.d. Insurance Code, Division 2: Classes of Insurance, Part 1: Fire and Marine Insurance, Chapter 8.5: Earthquake Insurance, §10088.5. Retrieved from: <http://ca.regstoday.com/law/ins/ca.regstoday.com/laws/ins/calawins_DIVISION2_PART1_CHAPTER8p5.aspx\#10088.5>. Accessed on: 23 July 2015.

Carter, R.L., 1986. Public Policy and Insurability. The Geneva Papers on Risk and Insurance 11(39), 145-156. 
Dana, D.A., Wiseman H.J., 2014, May. A market approach to regulating the energy revolution: Assurance bonds, insurance, and the certain and uncertain risks of hydraulic fracturing. Iowa Law Review.

Darrah, T., Vengosh, A., Jackson, R., Warner, N., Poreda, R., 2014. Noble gases identify the mechanisms of fugitive gas contamination in drinking water wells overlying the Marcellus and Barnett Shales. PNAS 111, 14076-14081.

Dybdahl, D., 2011. A User's Guide to Environmental Insurance. Society of Property and Casualty Underwriters. Web. Retrieved from: <http://www.erraonline.org/usersguide.pdf>. Accessed on: 23 July 2015.

Eberl, J., Jus, D., 2012. The year of the cat: Taxing nuclear risk with the help of capital markets. Energy Policy 51, 364-373.

Esch, M., 2012, 12 July. US insurer won't cover gas drill fracking exposure. Associated Press. Web. Retrieved from: < http://www.huffingtonpost.com/huff-wires/20120712/us-gasdrilling-insurance/>. Accessed on: 23 July 2015.

Frohlich, C., Ellsworth, W., Brown, W., Brunt, M., Luetgert, J., MacDonald, T., Walter, S., 2014. The 17 May 2012 M4.8 earthquake near Timpson, East Texas: An event possibly triggered by fluid injection. J. Geophys. Res.-Sol. Ea. 119, 581-593.

Gupta, P.K., 2008. Fundamentals of Insurance. Himalaya Publishing House, Mumbai.

Ha, Y., 2015, 15 April. Penn.: Fracking Exclusion Not Allowed In Homeowners Earthquake Endorsements. Insurance Journal. Web. Retrieved from: < http://www.insurancejournal.com/news/east/2015/04/15/364460.htm>. Accessed on: 3 March 2016. 
Hagström, E., Adams, J., 2012. Hydraulic fracturing: Identifying and managing the risks.

Environ. Claims. J. 24(2), 93-115.

Ingelson, A., Kleffner, A., Nielson, K., 2010. Long-term liability for carbon capture and storage in depleted North American oil and gas reservoirs - a comparative analysis. Energy Law Journal 31, 431-469.

Jackson, R., Vengosh, A., Darrah, T., Warner, N., Down, A., Poreda, R., 2013. Increased stray gas abundance in a subset of drinking water wells near Marcellus shale gas extraction. PNAS 110, 11250-11255.

Jacquet, J., Stedman, R., 2014. The risk of social-psychological disruption as an impact of energy development and environmental change. J. Environ. Plan. Manag. 57, 1285-1304.

Jo, J.Y., Kwon, Y.S., Lee, J.W., Park, J.S., Rho, B.H., Choi, W.I., 2013. Acute Respiratory Distress Due to Methane Inhalation. Tuberc. Respir. Dis. 74(3), 120-123.

Keranen, K.M., Weingart, M., Abers, G.A., Bekins, B.A., Ge, S., 2014. Sharp increase in central Oklahoma seismicity since 2008 induced by massive wastewater injection. Science 345 , $448-451$.

Kunreuther, H., 1997. Rethinking Society’s Management of Catastrophic Risks. The Geneva Papers on Risk and Insurance 22(83), 151-176.

Leverty, T.J., 2012. The Cost of Duplicative Regulation: Evidence from Risk Retention Groups. J. Insurance Regul. 79, 105-127.

Llewellyn, G., Dorman, F., Westland, J., Yoxtheimer, D., Grieve, P., Sowers, T., et al., 2015. Evaluating a groundwater supply contamination incident attributed to Marcellus Shale gas development. PNAS 112, 6325-6330. 
Maryland Institute for Applied Environmental Health, 2014. Potential Public Health Impacts of Natural Gas Development and Production in the Marcellus Shale in Western Maryland. College Park, MD: School of Public Health, University of Maryland.

McGarr, A., Bekins, B., Burkardt, N., Dewey, J., Earle, P., et al., 2015. Coping with earthquakes induced by fluid injection: Hazard may be reduced by managing injection activities. Science $347,830-831$.

McLeod, D., 2013, 24 February. Insurance coverage options for fracking risks are limited. Business Insurance. Web. Retrieved from: <http://www.businessinsurance.com/article/20130224/NEWS07/302249991>. Accessed on: 23 July 2015.

Nationwide. 2012, 13 July. Nationwide Statement Regarding Concerns About Hydraulic Fracturing. Web. Retrieved from: <http://www.nationwide.com/about-us/071312-nwstatement-on-fracking.jsp>. Accessed on: 23 July 2015.

New Brunswick Department of Health, 2012. Chief Medical Officer of Health's Recommendations Concerning Shale Gas Development in New Brunswick.

Nicholson, B., Blanson, K., Fair, A., 2012, 9 May. Fracking's Alleged Links to Water Contamination and Earthquakes. American Bar Association. Web. Retrieved from: <http://apps.americanbar.org/litigation/committees/energy/articles/spring2012-0512frackings-alleged-links-water-contamination-earthquakes.html>. Accessed on: 23 July 2015.

OECD, 2003. 'Natural Catastrophe Risk and Insurance', in Environmental Risks and Insurance: A Comparative Analysis of the Role of Insurance in the Management of EnvironmentRelated Risks. OECD Publishing. 
Ohio Department of Natural Resources (ODNR), Division of Oil and Gas Resources. 2015. Underground injection control (UIC). Retrieved from: http://oilandgas.ohiodnr.gov/industry/underground-injection-control. Accessed on 27 July 2015.

Osborn, S., Vengosh, A., Warner, N., Jackson, R., 2011. Methane contamination of drinking water accompanying gas-well drilling and hydraulic fracturing. PNAS 108, 8172-8176.

Petersen, M.D., Mueller, C.S., Moschetti, M.P., Hoover, S.M., Llenos, A.L., Ellsworth, W.L., Michael, A.J., Rubinstein, J.L., McGarr, A.F., and Rukstales, K.S., 2016. 2016 One-year seismic hazard forecast for the Central and Eastern United States from induced and natural earthquakes: U.S. Geological Survey Open-File Report 2016-1035.

Rafferty, M.A., Limonik, E., 2013. Is shale gas drilling an energy solution or public health crisis? Public Health Nurs. 30, 454-462.

Rozell, D., Reaven, S., 2012. Water pollution risk associated with natural gas extraction from the Marcellus Shale. Risk Analysis 32, 1382-1393.

Schremmer, J., 2011. Avoidable "Fraccident”: An argument against strict liability for hydraulic fracturing. University of Kansas Law Review 2011, 1215-1255.

Skoumal, R., M. Brudzinski and B. Currie. 2015. Microseismicity induced by deep wastewater injection in southern Trumbull County, Ohio. Seismological Research Letters, published online before print (8 July 2015).

Souther, S., Tingley, M.W., Popescu, V.D., Hayman, D.T.S., Ryan, M.E., Graves, T.A., Hartl, B., Terrell, K, 2014. Biotic impacts of energy development from shale: Research priorities and knowledge gaps. Front. Ecol. Environ. 12, 330-338. 
Sumy, D.F., Cochran, E.S., Keranen, K.M., Wei, M., Abers, G.A., 2014. Observations of static Coulomb stress triggering of the November 2011 M5.7 Oklahoma earthquake sequence. J. Geophys. Res.-Sol. Ea. 119, 1904-1923.

Swartz, T., 2011. Hydraulic fracturing: Risks and risk management. Nat. Resour. Environ. 26, 30-32 and 59.

U.S. Environmental Protection Agency, 2015. Review of State and Industry Spill Data: Characterization of Hydraulic Fracturing-Related Spills. Office of Research and Development, Washington, DC. EPA/601/R-14/001.

Vann, A., Murrill, B.J., Tiemann, M., 2014, 26 September. Hydraulic Fracturing: Selected Legal Issues. Congressional Research Service. Web. Retrieved from: $<$ http://fas.org/sgp/crs/misc/R43152.pdf >. Accessed on: 23 July 2015.

Vengosh, A., Jackson, R., Warner, N., Darrah, T., Kondash, A., 2014. A critical review of the risks to water resources from unconventional shale gas development and hydraulic fracturing in the United States. Environ. Sci. Technol. 48, 8334-8348.

Waeger, A., 2013, 23 September. Current Insurance Policies for Insuring Against Environmental Risks. Greenbaum, Rowe, Smith \& Davis LLP. Web. Retrieved from: $<$ http://www.greenbaumlaw.com/insights-publications-307.html>. Accessed on: 23 July 2015.

Weiss, G.N.F., Bostandzic, D., Irresberger, F., 2013, 20 August. Catastrophe Bonds and Systemic Risk. 26th Australasian Finance and Banking Conference.

Wiseman, H., 2014. The capacity of states to govern shale gas development risks. Environ. Sci. Technol. 48, 8376-8387. 
Zilk, C., 2011, 31 July. Permanent disposal-well moratorium issued. Arkansas Online. Web.

Retrieved from: <http://www.arkansasonline.com/news/2011/jul/31/permanent-disposalwell-moratorium-issued-20110731/>. Accessed on: 23 July 2015. 